Published in final edited form as:

Nutr Res. 2015 May ; 35(5): 421-430. doi:10.1016/j.nutres.2015.04.004.

\title{
Trace elements as predictors of preeclampsia in type 1 diabetic pregnancy
}

\author{
Arpita Basu ${ }^{1}$, Jeremy Y. Yu², Alicia J. Jenkins ${ }^{2,3}$, Alison J. Nankervis ${ }^{4}$, Kristian F. \\ Hanssen $^{5,6}$, Tore Henriksen ${ }^{7}$, Bjørg Lorentzen ${ }^{7}$, Satish K. Garg ${ }^{8}$, M. Kathryn Menard ${ }^{9}$, \\ Samar M. Hammad ${ }^{10}$, James A. Scardo ${ }^{11}$, Christopher E. Aston ${ }^{12}$, and Timothy J. Lyons ${ }^{2,13}$ \\ ${ }^{1}$ Department of Nutritional Sciences, Oklahoma State University, Stillwater, OK, USA \\ ${ }^{2}$ Centre for Experimental Medicine, Queen's University of Belfast, Belfast, Northern Ireland, UK \\ ${ }^{3}$ University of Sydney, NHMRC Clinical Trials Centre, Camperdown, Sydney, NSW, Australia \\ ${ }^{4}$ Diabetes Service, The Royal Women's Hospital, Melbourne, Australia \\ ${ }^{5}$ Department of Endocrinology, Oslo University Hospital, Oslo, Norway \\ ${ }^{6}$ Institute of Clinical Medicine, University of Oslo, Oslo, Norway \\ ${ }^{7}$ Department of Gynecology and Obstetrics, Oslo University Hospital, Oslo, Norway \\ ${ }^{8}$ Barbara Davis Center for Childhood Diabetes, University of Colorado Health Sciences Center, \\ Aurora, Colorado, USA \\ ${ }^{9}$ Division of Maternal Fetal Medicine, University of North Carolina, Chapel Hill, North Carolina, \\ USA \\ ${ }^{10}$ Department of Regenerative Medicine and Cell Biology, Medical University of South Carolina, \\ Charleston, South Carolina, USA \\ ${ }^{11}$ Spartanburg Regional Medical Center, Spartanburg, South Carolina, USA \\ ${ }^{12}$ Department of Pediatrics, University of Oklahoma Health Sciences Center, Oklahoma City, \\ Oklahoma, USA \\ ${ }^{13}$ Section of Endocrinology and Diabetes, University of Oklahoma Health Sciences Center, \\ Oklahoma City, Oklahoma, USA
}

\footnotetext{
(C) 2015 Published by Elsevier Inc.

Correspondence: Arpita Basu, PhD, RD, Associate Professor, Department of Nutritional Sciences, 301 Human Sciences, Oklahoma State University, Stillwater, OK 74078-6141, Phone 405-744-4437, Fax 405-744-1357, arpita.basu@ okstate.edu.

The authors have no conflict of interest

Financial disclosure: This work was supported by research grants from the Juvenile Diabetes Research Foundation (JDRF 1-2001-844) and by NIH (National Center for Research Resources) Grants M01-RR-1070 and M01-RR-14467 (to the General Clinical Research Centers at the Medical University of South Carolina and the University of Oklahoma Health Sciences Center, respectively). Support from Novo Nordisk enabled the participation of the Barbara Davis Diabetes Center for Childhood Diabetes. Support was also provided by the Dean's Research Incentive award at Oklahoma State University. This publication was made possible by NIH Grant P20 RR 024215 from the Centers of Biomedical Research Excellence Program of the National Center for Research Resources.

Publisher's Disclaimer: This is a PDF file of an unedited manuscript that has been accepted for publication. As a service to our customers we are providing this early version of the manuscript. The manuscript will undergo copyediting, typesetting, and review of the resulting proof before it is published in its final citable form. Please note that during the production process errors may be discovered which could affect the content, and all legal disclaimers that apply to the journal pertain.
} 


\section{Abstract}

Preeclampsia (PE) affects approximately 5\% of all pregnancies, but is increased several-fold in women with pre-gestational type 1 diabetes mellitus (T1DM). Increased oxidative stress and altered maternal plasma trace elements that modulate the antioxidant system have been implicated in PE. In non-diabetic women, increased plasma copper and iron, and decreased manganese, selenium, and zinc have been associated with PE in cross-sectional studies. In a longitudinal study, we hypothesized that plasma levels of trace elements differ between T1DM women with vs. without subsequent PE. Samples were collected during the first (gestation $12.2 \pm 1.9$ weeks, (mean $\pm \mathrm{SD})$ ), second ( $21.6 \pm 1.5$ weeks), and third ( $31.5 \pm 1.7$ weeks) trimesters of pregnancy, all before the onset of PE. We compared 23 T1DM women who subsequently developed PE with 24 T1DM women who remained normotensive; and we included 19 non-diabetic (non-DM) normotensive pregnant women as reference controls. Trace elements were measured using inductively coupled plasma mass spectroscopy (ICP-MS). In T1DM women with subsequent PE vs. normotensive, only plasma zinc was significantly higher at the first trimester, while copper:zinc and copper:HDL-cholesterol ratios were higher throughout gestation (all $\mathrm{p}<0.05$ ). These findings persisted after adjustment for covariates. Higher copper:zinc ratios may contribute to oxidative stress in T1DM women who develop PE. Ratio of pro- to anti-oxidant factors may predict risk for $\mathrm{PE}$ in diabetic pregnancies more effectively than individual trace element levels.

\section{Keywords}

Preeclampsia; Type 1 diabetes; copper; zinc; selenium; oxidative stress

\section{Introduction}

Preeclampsia (PE), a pregnancy-specific syndrome characterized by hypertension, proteinuria, and edema, is one of the leading causes of maternal mortality and preterm delivery, and is associated with adverse long-term outcomes for both mother and child. ${ }^{1,2}$ Its etiology is unclear, but evidence implicates placental hypoxia leading to oxidative stress, inflammation, and maternal endothelial dysfunction. ${ }^{3,4}$ Maternal Type 1 diabetes mellitus (T1DM), a condition associated with elevated oxidative stress and vascular dysfunction, increases the risk for PE about four-fold. ${ }^{5,6}$ There is little information available concerning associations of maternal pro- and anti-oxidant biomarkers with the subsequent development of PE, especially in presence of pre-gestational T1DM. We previously reported that altered maternal circulating antioxidant vitamins and inflammatory biomarkers are significantly associated with subsequent onset of PE in a well-characterized cohort of women with pregestational T1DM. ${ }^{7,8}$ We now aim to investigate the associations of maternal plasma trace elements, which are relevant to oxidative stress and antioxidant defense, with the subsequent development of PE in the same cohort.

Trace elements play a crucial role in fetal growth and development, ${ }^{9,}, 10$ and levels of trace elements that modulate the antioxidant defense system, such as copper, iron, manganese, selenium, and zinc change during the course of normal pregnancy. ${ }^{11-14}$ Copper, manganese and zinc are essential trace elements for optimal function of the antioxidant enzyme, superoxide dismutase (SOD), ${ }^{15}, 16$ while selenium plays an important role in antioxidant 
functions of the glutathione enzyme system. ${ }^{17}$ Also, iron and copper are redox transition elements, and when present in excess could promote oxidative stress and endothelial cell damage. ${ }^{16}$ Associations of these trace elements with pregnancy-related hypertensive disorders, including PE, have been described, but mostly in case-control studies conducted late in pregnancy in non-diabetic women. The results are conflicting: maternal copper, iron, manganese, selenium, and zinc were decreased in the presence of PE in most studies ${ }^{18-23}$; however in some, copper, iron, and zinc were elevated in $\mathrm{PE}^{24-26}$ and in others there were no associations with PE. ${ }^{27,} 28$ Clearly, in these studies, any such associations could be a result, not a cause, of PE, or could be entirely unrelated: thus longitudinal studies are needed.

In the present prospective study, we hypothesized that maternal plasma trace elements, and specifically the ratios of pro-oxidant versus antioxidant factors, may act as markers for the subsequent onset of PE. Thus, we sought to determine concentrations of plasma copper, iron, manganese, selenium, and zinc at early, mid and late gestational phases, and related it to the subsequent development of PE. We also examined the ratios of copper, iron, and manganese with zinc, based on their inter-relationships in regulating the antioxidant defense system, as well as with HDL cholesterol, since HDL has known antioxidant functions. Our primary comparisons are between pre-gestational T1DM women who later developed PE and those who remained normotensive. We included a group of non-diabetic, normotensive pregnant women to serve as reference controls, and in a secondary analysis, we compare this group to the normotensive diabetic women.

\section{Methods}

We performed a sub-study of a previously-described prospective cohort of 151 non-Hispanic white women with T1DM and 24 non-diabetic participants enrolled during the first trimester of pregnancy and followed until delivery. ${ }^{29}$ Clinical data and specimens were collected at each trimester (visit 1: $12.2 \pm 1.9$ weeks; visit 2: $21.6 \pm 1.5$ weeks; and visit 3: $31.5 \pm 1.7$ weeks of gestation [mean \pm SD]; no overlap). Visit 3 was before PE onset. Subjects were requested to fast overnight, and serum, plasma, and urine samples were obtained before any exogenous insulin was taken. The study was approved by the institutional review boards of participating centers in Norway, Australia, and the U.S. Exclusion criteria were renal impairment (including microalbuminuria), cardiovascular disease, hypertension, or any other significant medical problem pre-pregnancy or at visit 1 . PE was defined as new-onset hypertension (>140/90 $\mathrm{mmHg}$ ) after 20 weeks' gestation in a previously normotensive woman, accompanied by proteinuria ( $>300 \mathrm{mg} / 24 \mathrm{~h}$ ). Of the 26 diabetic women who developed PE (DM PE +$)^{29}$, samples from 23 were available for this sub-study (sample attrition). Of the 26 selected DM PE- cases, matched on the basis of age, diabetes duration, $\mathrm{HbA1c}$ and parity, samples from 24 were available for this study (sample attrition). For reference values, 19 of 24 pregnant, non-diabetic, non-PE women (DM-) were also studied (three were previously excluded as described ${ }^{29}$; two due to sample attrition).

\subsection{Laboratory analyses}

Plasma lipids, including HDL-cholesterol, were analyzed at the OUHSC Clinical Laboratory. Plasma levels of copper $\left({ }^{63} \mathrm{Cu} \&{ }^{65} \mathrm{Cu}\right)$, iron $\left({ }^{54} \mathrm{Fe} \&{ }^{57} \mathrm{Fe}\right)$, manganese $\left({ }^{55} \mathrm{Mn}\right)$, 
selenium $\left({ }^{82} \mathrm{Se}\right)$, and zinc $\left({ }^{66} \mathrm{Zn}\right)$ were measured using inductively coupled plasma quadrupole mass spectroscopy (Elan 9000; Perkin Elmer, Norwalk, CT) as described. ${ }^{30}$ All plasma samples were diluted 20 -fold ( $200 \mu \mathrm{L}$ diluted to $4 \mathrm{~mL}$ ) with $0.1 \%$ nitric oxide (GFS Chemicals, Powell, OH) in ultra-pure water. Standard solutions of selected trace elements were prepared by dilution of certified standard solutions (Perkin Elmer, Norwalk, CT). The calibration standards were prepared in $0.1 \%$ nitric acid solution at 0,50 , and $100 \mu \mathrm{g} / \mathrm{L}$. All samples and standards were spiked with $10 \mu \mathrm{g} / \mathrm{L}$ gallium as an internal standard (Perkin Elmer, Norwalk, CT). Polypropylene plastic ware (Sarstedt, Inc., Newton, NC) was used for reagent and sample preparation to avoid metal contamination. Quality control samples (Utak Laboratories, Inc., Valencia, CA) were used to verify method performance and confirm obtained values were within recommended ranges. Quantitative analyses were performed using the scanning mode of data acquisition. For each element, peak area (signal) was divided (normalized) by the signal from the internal standard. Based on triplicate analyses, the estimated average interassay CV for copper, iron, manganese, selenium, and zinc was in the range of $2-7 \%$.

\subsection{Statistical analyses}

Baseline data at visit 1 are shown as means \pm SD. Maternal plasma trace elements (copper, iron, manganese, selenium, and zinc) and their ratios (copper:zinc, iron:zinc, manganese:zinc, copper HDL cholesterol, zinc:HDL cholesterol) are presented as means \pm SE. Our primary analysis examined differences between women with T1DM who subsequently developed PE (DM PE+) versus those who remained normotensive (DM PE-). Cross-sectional between-group analyses of maternal trace elements and their ratios were performed at each visit using a general linear model analysis with and without covariates. The covariates considered were the visit 1 values of $\mathrm{BMI}, \mathrm{HbA}_{1 \mathrm{c}}$, mean arterial pressure, as well as age at onset of diabetes and duration of diabetes. Covariates were selected according to baseline differences, known associations with PE, or both. In the simpler case with no covariates this is equivalent to a t-test between DM PE+ and DM PE-. Longitudinal between-group analyses across all visits (overall) were performed using a generalized estimating equation (GEE) analysis with and without covariates. Including covariates had little effect on means and no effect on conclusions so results of analyses without covariates are reported. In the simpler case with no covariates, this is equivalent to repeated measures ANOVA. All tests were two-tailed, with $P<0.05$ described as significant for the purposes of discussion. We also performed a secondary analysis to compare DM PE- and DMpregnancies to discern changes attributable to diabetes. Statistical analyses used IBM SPSS Statistics (IBM Corp. Released 2011. IBM SPSS Statistics for Windows, Version 20.0. Armonk, NY: IBM Corp).

\section{Results}

\subsection{Baseline characteristics}

As shown in Table 1, body mass index (BMI) was significantly higher and HDL-cholesterol was significantly lower in the DM PE+ when compared to the DM PE- group ( $<<0.05)$. The age of onset of T1DM tended to be lower in diabetic women who later developed PE vs. those who did not $(\mathrm{p}<0.1)$. When comparing DM PE- vs. DM- groups, the diabetic 
normotensive group had, as expected, significantly higher $\mathrm{HbA1c}(\mathrm{p}<0.05)$, and also tended to have lower serum triglycerides than the non-diabetic group $(\mathrm{p}<0.1)$.

\subsection{Copper and Iron (Figure 1)}

In the primary comparisons between DM PE+ and DM PE-, plasma copper $\left({ }^{63} \mathrm{Cu} \&{ }^{65} \mathrm{Cu}\right)$ and iron $\left({ }^{54} \mathrm{Fe} \&{ }^{57} \mathrm{Fe}\right)$ were not significantly different at any trimester prior to PE onset (Figures 1A-1D). Longitudinal analyses throughout gestation also revealed no significant differences between the two diabetic groups prior to PE onset. In secondary analyses, DM PE- vs. DM- had higher plasma copper only at the third trimester, and specifically, plasma ${ }^{63} \mathrm{Cu}$ was significantly higher in DM PE- at this gestational age (Figure 1A; $\mathrm{p}<0.05)$. No differences were noted in either form of plasma iron between DM PE- vs. DM - at any of the trimesters (Figure 1C and 1D). Again, longitudinal analyses showed no differences in maternal copper and iron due to the presence of diabetes. These conclusions persisted after adjustment for covariates.

\subsection{Manganese, Selenium, and Zinc (Figure 2)}

Primary analyses revealed no significant differences in case of plasma manganese ( $\left.{ }^{55} \mathrm{Mn}\right)$ and selenium $\left({ }^{82} \mathrm{Se}\right.$ ) levels between DM PE+ and DM PE- (Figures 2A and 2B). Plasma zinc $\left({ }^{66} \mathrm{Zn}\right)$ was significantly higher, though only at the first trimester, in T1DM women who later developed $\mathrm{PE}(\mathrm{p}<0.05$; Figure 2C). However, longitudinal analyses revealed no overall significance in zinc levels in the diabetic group who developed PE compared to those who remained normotensive. In secondary analyses, DM PE- vs. DM- had significantly higher plasma manganese only at the third trimester ( $\mathrm{p}<0.05$; Figure $2 \mathrm{~A}$ ), higher plasma selenium at the first and third trimesters ( $<<0.05$; Figure $2 B$ ), but no differences in plasma zinc (Figure 2C). Longitudinal analyses revealed overall plasma manganese and selenium, but not zinc to be significantly higher in the DM PE- compared to the non-diabetic controls $(\mathrm{p}<0.05)$. We excluded an individual (DM PE-) with $\mathrm{Mn}>20 \mathrm{mg} / \mathrm{L}$ from the reported analyses. These findings persisted after adjustment for covariates.

\subsection{Ratios of trace elements (Figure 3)}

Plasma $\mathrm{Cu}: \mathrm{Zn}$ values (for both copper isotopes) were observed to be significantly lower at the first trimester, but higher at the third trimester, in DM PE+ vs DM PE- women ( $p<0.05$; Figure 3A and 3B). Longitudinal analyses also revealed significantly higher ratios of copper to zinc throughout pregnancy in diabetic women who later developed $\mathrm{PE}$ versus normotensive controls $(\mathrm{p}<0.05)$. No significant cross-sectional or longitudinal differences were noted between the two diabetic groups for plasma Fe:Zn (Figure 3C and 3D) and $\mathrm{Mn}: \mathrm{Zn}$ (Figure 3E). Secondary analyses of these ratios revealed no differences between the diabetic normotensive subjects and the non-diabetic controls at any visit or throughout pregnancy.

\subsection{Ratios of trace elements with HDL cholesterol (Figure 4)}

While no significant differences were noted in copper:HDL cholesterol between DM PE+ vs. DM PE- at any trimester, zinc:HDL cholesterol was significantly higher only at the first trimester in T1DM women who later developed $\mathrm{PE}(\mathrm{p}<0.05$; Figure 4C). Longitudinal 
analyses revealed significantly higher ratios of copper (both isotopes) and zinc with HDLcholesterol in DM PE+ compared to the DM PE- group ( $p<0.05)$, overall throughout gestation. Secondary analyses revealed no differences between the diabetic normotensive and the non-diabetic controls at each visit or throughout pregnancy. When data were analyzed by severity of PE (moderate PE, $N=16$; severe PE, $n=7$ ), we found significant differences between the two groups only in case of $\mathrm{Zn}$ :HDL cholesterol which was higher at second and third trimesters in diabetic women who developed severe PE compared to those exhibiting moderate $\mathrm{PE}$ ( $\mathrm{p}<0.05$; data not shown).

\section{Discussion}

Copper and iron are redox-active transition elements and can catalyze the formation of free radicals, thereby leading to the oxidative modification of lipids and proteins characteristic of chronic conditions like diabetes. ${ }^{16}$ While most of the cross-sectional studies in non-diabetic women have reported significantly higher copper and iron in PE cases vs. controls, ${ }^{24-26,31,32}$ a few studies found no differences in these elements in presence vs. absence of PE. ${ }^{27}$ In a recently reported prospective study in non-diabetic women, maternal plasma copper was significantly elevated in early pregnancy among those who subsequently developed PE compared to the controls. ${ }^{33}$ In our prospective study of T1DM women, copper and iron levels were generally higher, though not significantly so, at the third trimester in the diabetic group that subsequently developed PE. It is possible that the clinical manifestation of PE is associated with more pronounced differences in these elements compared to the preclinical phase examined in our longitudinal study. Some of the discrepancies between studies may be explained by methodological differences in trace element analyses. Most of the previously reported case-control studies have used spectrophotometric assays based on atomic absorption, while we used the inductively coupled plasma mass spectroscopy which is specific in quantifying ions separated on the basis of their mass-to-charge ratio. The natural isotopes of trace elements, including copper and iron examined in our study have been widely analyzed in human nutritional studies of mineral absorption and retention. ${ }^{34-37}$ Future studies must also examine the incorporation of copper and iron into specific cells, such as red blood cells, placenta, as well as their fecal excretion, to further define the associations of these trace elements with PE.

Manganese, selenium, and zinc are essential trace elements for the antioxidant defense system, especially as co-factors for enzymes such as superoxide dismutase and the glutathione enzyme system that scavenge free radicals and protect against oxidative damage. ${ }^{15-17}$ Thus, case-control studies have mostly reported lower maternal plasma manganese, selenium, and/or zinc in presence of PE in non-diabetic women. ${ }^{18-23}$ In our study, manganese and selenium were not significantly different prior to PE onset between the two diabetic groups, though levels at the third trimester were lower in those who later developed PE than in those who remained normotensive. In the case of zinc, we observed significantly higher levels in the diabetic group who later developed PE, but only at the first trimester, and overall zinc levels were not different throughout pregnancy between the two groups. Maternal zinc levels have been shown to be elevated in a few studies of pregnancies complicated by PE in non-diabetic women. ${ }^{26,38}$ In a cross-sectional study at the third trimester, Borella et al. reported significantly higher maternal plasma zinc in cases of 
diabetes with fetal growth retardation, but not those with PE, in comparison with nondiabetic healthy pregnant controls. ${ }^{39}$ Furthermore, zinc uptake by the human placenta and in experimental diabetic animals has been shown to be modulated by several factors including maternal tissue zinc concentrations, gestational age, and diabetes. ${ }^{40,41}$ Though the exact mechanism is not clear, the observed higher maternal zinc levels in our diabetic PE group in the first trimester may be due to reduced placental zinc uptake based on early placental dysfunction ${ }^{4}$. It should however be noted that overall serum zinc levels in our T1DM women were above the thresholds associated with 'zinc deficiency' in other studies of nondiabetic women. $.^{9}, 42$ Our findings deserve further investigation in larger trials of diabetic women at increased risk for PE, especially involving simultaneous determination of maternal serum and placental zinc status.

Interestingly, we found that copper:zinc ratios are modulated throughout gestation, while no differences were noted in iron:zinc or manganese:zinc ratios. We noted higher values of copper:zinc throughout pregnancy in the diabetic women who subsequently developed PE vs. those who did not. These ratios have previously been used as indices of oxidative stress, and have been reported as significantly associated with the presence of PE in non-diabetic women in some studies, ${ }^{18,20,26,31}$; other studies, however, have shown no associations with PE. ${ }^{19,39}$ Again, these are cross-sectional studies in women with confirmed PE, and provide no insight into the modulation of trace element ratios earlier in gestation, prior to PE onset. Our longitudinal study thus reveals significant imbalance in maternal ratios of copper, an element with demonstrated pro-oxidant effects, ${ }^{16}$ with zinc, which is associated with antioxidant effects ${ }^{43}$, prior to the onset of PE. These observations deserve further confirmation in future, larger, prospective studies.

HDL cholesterol has been associated with antioxidant and anti-inflammatory functions that support its inverse correlation with cardiovascular disease. ${ }^{44}$ The antioxidant capacity of HDL has also been shown to be lower in patients with T1DM versus non-diabetic controls. ${ }^{45}$ In our study, HDL-cholesterol was also observed to be lower at the first trimester in the diabetic PE group when compared to the normotensive group. Increased susceptibility of serum lipids to oxidation has been reported in $\mathrm{PE},{ }^{46}$ though no prospective associations of HDL-cholesterol with trace elements have been reported in pregnancies complicated by T1DM and/or PE. We observed significantly higher ratios of copper:HDL cholesterol and zinc:HDL cholesterol in T1DM women who later developed PE throughout pregnancy. Zinc supplementation in randomized controlled trials has been shown to lower HDLcholesterol, ${ }^{47}$ potentially influencing antioxidant status and endothelial function, factors that are implicated in the pathogenesis of PE. These associations must be further defined in larger studies of PE in T1DM.

Our secondary analyses revealed that pregnancies complicated by T1DM appear to be associated with higher levels of copper, manganese, and selenium than non-diabetic pregnancies. These differences were most pronounced at the third trimester. These findings are similar to other reported studies showing altered antioxidant and trace element status in pregnancies complicated by diabetes. ${ }^{39,} 48$ However, there is a lack of data from longitudinal studies assessing differences in trace elements involved in the antioxidant system in diabetic 
vs. non-diabetic pregnancies. Our findings reveal some abnormalities in these elements in the presence of maternal T1DM that may create a 'fertile soil' for the development of PE.

Large-scale community intervention studies have identified roles for micronutrient supplementation, especially of iron, zinc, and selenium, in improving pregnancy outcomes and infant mortality. ${ }^{49,} 50 \mathrm{~A}$ few trials have shown reduced incidence of PE in non-diabetic women following administration of a combination of essential trace elements, but do not report maternal levels of these trace elements. ${ }^{51,52}$ Thus, carefully controlled trials are needed to examine the effects of trace element supplementation, with or without other antioxidant nutrients, in reducing risks of PE in diabetic women.

Our study has several limitations. We have small sample sizes in the two diabetic groups, limiting statistical power. We did not measure activity of antioxidant enzymes and other biomolecules, such as transferrin and ceruloplasmin that modulate the activity and metabolism of the essential trace elements. Also, our study was limited to non-Hispanic white women, and thus do not address the issue of ethnic differences in the prevalence of PE. Finally, we did not record maternal dietary intakes of these essential elements. In this regard, most other reported studies also failed to adjust for dietary intake, although one reported differences in maternal trace elements associated with $\mathrm{PE}$, despite similar nutrient intake in those with and without PE. ${ }^{23}$

Overall, our hypothesis is supported by our data. We found higher maternal plasma zinc in early pregnancy, and the ratios of pro-oxidant elements, such as copper, with antioxidant molecules, such as zinc and HDL cholesterol were significantly elevated throughout pregnancy in diabetic women who subsequently developed PE. We also found diabetes to be associated with higher copper, manganese, and selenium, mostly in late pregnancy, when compared to non-diabetic pregnant women. Thus, the balance between maternal pro-oxidant and antioxidant biomolecules may deserve special attention in assessing risks and mechanisms of PE in women with pre-gestational T1DM. Future studies in T1DM pregnancy are needed to explore these findings, and in intervention studies, to delineate the role of essential trace element therapy in the prevention and medical management of PE.

\section{Acknowledgments}

We acknowledge the following for technical or clinical assistance: Sandra Peterson (Oklahoma State University); J. Mauldin and M. Myers (Medical University of South Carolina); Jill Cole and Nancy Sprouse (Spartanburg Regional Hospital); Myrra Windau (University of Colorado); C. Knight, J. Conn, P. England, S. Hiscock, J. Oats, and P. Wein (University of Melbourne); and Julie Stoner and Lori Doyle (University of Oklahoma). At the University of Oklahoma, Kenneth Wilson assisted with sample processing and the conduct of laboratory work. A.J.J., A.J.N., K.F.H., T.H., B.L., S.K.G., M.K.M., S.M.H., J.A.S., and T.J.L. designed and conducted research; C.E.A. analyzed data; A.B., J.Y.Y., and T.J.L. conducted research and wrote the paper. T.J.L. had primary responsibility for final content. All authors read and approved the final manuscript.

\section{List of abbreviations}
Cu Copper
DM- non-diabetic normotensive pregnant controls
DM PE+ $\quad$ type 1 diabetic women who developed PE 


$\begin{array}{ll}\text { DM PE- } & \text { type } 1 \text { diabetic women who did not develop PE } \\ \text { GEE } & \text { generalized estimating equations } \\ \text { ICP-MS } & \text { inductively coupled plasma mass spectroscopy } \\ \text { Fe } & \text { iron } \\ \text { Mn } & \text { manganese } \\ \text { PE } & \text { preeclampsia } \\ \text { Se } & \text { selenium } \\ \text { SOD } & \text { superoxide dismutase } \\ \text { T1DM } & \text { type } 1 \text { diabetes mellitus } \\ \text { Zn } & \text { zinc }\end{array}$

\section{References}

1. Roberts JM, Pearson G, Cutler J, Lindheimer M. Summary of the NHLBI Working Group on Research on Hypertension During Pregnancy. Hypertension. 2003; 41:437-45. [PubMed: 12623940]

2. Tenhola S, Rahiala E, Martikainen A, Halonen P, Voutilainen R. Blood pressure, serum lipids, fasting insulin, and adrenal hormones in 12-year-old children born with maternal preeclampsia. J Clin Endocrinol Metab. 2003; 88:1217-22. [PubMed: 12629109]

3. Roberts JM, Hubel CA. Is oxidative stress the link in the two-stage model of pre-eclampsia? Lancet. 1999; 354:788-9. [PubMed: 10485715]

4. Redman CW, Sargent IL. Latest advances in understanding preeclampsia. Science. 2005; 308:15924. [PubMed: 15947178]

5. Hanson U, Persson B. Outcome of pregnancies complicated by type 1 insulin-dependent diabetes in Sweden: acute pregnancy complications, neonatal mortality and morbidity. Am J Perinatol. 1993; 10:330-3. [PubMed: 8397576]

6. Evers IM, de Valk HW, Visser GH. Risk of complications of pregnancy in women with type 1 diabetes: nationwide prospective study in the Netherlands. BMJ. 2004; 328:915. [PubMed: 15066886]

7. Azar M, Basu A, Jenkins AJ, Nankervis AJ, Hanssen KF, Scholz H, et al. Serum carotenoids and fat-soluble vitamins in women with type 1 diabetes and preeclampsia: a longitudinal study. Diabetes Care. 2011; 34:1258-64. [PubMed: 21498785]

8. Du M, Basu A, Fu D, Wu M, Centola M, Jenkins AJ, et al. Serum inflammatory markers and preeclampsia in type 1 diabetes: a prospective study. Diabetes Care. 2013; 36:2054-61. [PubMed: 23393212]

9. Black RE, Victora CG, Walker SP, Bhutta ZA, Christian P, de Onis M, et al. Maternal and child undernutrition and overweight in low-income and middle-income countries. Lancet. 2013; 382:42751. [PubMed: 23746772]

10. Black RE. Micronutrients in pregnancy. Br J Nutr. 2001; 85 (Suppl 2):S193-7. [PubMed: 11509110]

11. Izquierdo Alvarez S, Castanon SG, Ruata ML, Aragues EF, Terraz PB, Irazabal YG, Gonzalez EG, Rodriguez BG. Updating of normal levels of copper, zinc and selenium in serum of pregnant women. J Trace Elem Med Biol. 2007; 21 (Suppl 1):49-52. [PubMed: 18039497]

12. Liu J, Yang H, Shi H, Shen C, Zhou W, Dai Q, Jiang Y. Blood copper, zinc, calcium, and magnesium levels during different duration of pregnancy in Chinese. Biol Trace Elem Res. 2010; 135:31-7. [PubMed: 19669713] 
13. Tabrizi FM, Pakdel FG. Serum Level of Some Minerals during Three Trimesters of Pregnancy in Iranian Women and Their Newborns: A Longitudinal Study. Indian J Clin Biochem. 2014; 29:174-80. [PubMed: 24757299]

14. Takser L, Lafond J, Bouchard M, St-Amour G, Mergler D. Manganese levels during pregnancy and at birth: relation to environmental factors and smoking in a Southwest Quebec population. Environ Res. 2004; 95:119-25. [PubMed: 15147916]

15. Avila DS, Puntel RL, Aschner M. Manganese in health and disease. Met Ions Life Sci. 2013; 13:199-227. [PubMed: 24470093]

16. Valko M, Leibfritz D, Moncol J, Cronin MT, Mazur M, Telser J. Free radicals and antioxidants in normal physiological functions and human disease. Int J Biochem Cell Biol. 2007; 39:44-84. [PubMed: 16978905]

17. Rayman MP. The importance of selenium to human health. Lancet. 2000; 356:233-41. [PubMed: 10963212]

18. Sarwar MS, Ahmed S, Ullah MS, Kabir H, Rahman GK, Hasnat A, Islam MS. Comparative study of serum zinc, copper, manganese, and iron in preeclamptic pregnant women. Biol Trace Elem Res. 2013; 154:14-20. [PubMed: 23749478]

19. Al-Jameil N, Tabassum H, Al-Mayouf H, Aljohar HI, Alenzi ND, Hijazy SM, Khan FA. Analysis of serum trace elements-copper, manganese and zinc in preeclamptic pregnant women by inductively coupled plasma optical emission spectrometry: a prospective case controlled study in Riyadh, Saudi Arabia. Int J Clin Exp Pathol. 2014; 7:1900-10. [PubMed: 24966900]

20. Kumru S, Aydin S, Simsek M, Sahin K, Yaman M, Ay G. Comparison of serum copper, zinc, calcium, and magnesium levels in preeclamptic and healthy pregnant women. Biol Trace Elem Res. 2003; 94:105-12. [PubMed: 12958401]

21. Kim J, Kim YJ, Lee R, Moon JH, Jo I. Serum levels of zinc, calcium, and iron are associated with the risk of preeclampsia in pregnant women. Nutr Res. 2012; 32:764-9. [PubMed: 23146773]

22. Ghaemi SZ, Forouhari S, Dabbaghmanesh MH, Sayadi M, Bakhshayeshkaram M, Vaziri F, Tavana Z. A prospective study of selenium concentration and risk of preeclampsia in pregnant Iranian women: a nested case-control study. Biol Trace Elem Res. 2013; 152:174-9. [PubMed: 23354545]

23. Tande DL, Ralph JL, Johnson LK, Scheett AJ, Hoverson BS, Anderson CM. First trimester dietary intake, biochemical measures, and subsequent gestational hypertension among nulliparous women. J Midwifery Womens Health. 2013; 58:423-30. [PubMed: 23895215]

24. Serdar Z, Gur E, Develioglu O. Serum iron and copper status and oxidative stress in severe and mild preeclampsia. Cell Biochem Funct. 2006; 24:209-15. [PubMed: 15898124]

25. Siddiqui IA, Jaleel A, Kadri HM, Saeed WA, Tamimi W. Iron status parameters in preeclamptic women. Arch Gynecol Obstet. 2011; 284:587-91. [PubMed: 20981433]

26. Harma M, Kocyigit A. Correlation between maternal plasma homocysteine and zinc levels in preeclamptic women. Biol Trace Elem Res. 2005; 104:97-105. [PubMed: 15894810]

27. Adam B, Malatyalioglu E, Alvur M, Talu C. Magnesium, zinc and iron levels in pre-eclampsia. J Matern Fetal Med. 2001; 10:246-50. [PubMed: 11531150]

28. Rezende VB, Barbosa F Jr, Palei AC, Cavalli RC, Tanus-Santos JE, Sandrim VC. Correlations among antiangiogenic factors and trace elements in hypertensive disorders of pregnancy. $\mathrm{J}$ Trace Elem Med Biol. 2015; 29:130-5. [PubMed: 25053574]

29. Yu Y, Jenkins AJ, Nankervis AJ, Hanssen KF, Scholz H, Henriksen T, et al. Anti-angiogenic factors and pre-eclampsia in type 1 diabetic women. Diabetologia. 2009; 52:160-8. [PubMed: 18985316]

30. Hubbs-Tait L, Mulugeta A, Bogale A, Kennedy TS, Baker ER, Stoecker BJ. Main and interaction effects of iron, zinc, lead, and parenting on children's cognitive outcomes. Dev Neuropsychol. 2009; 34:175-95. [PubMed: 19267294]

31. Fenzl V, Flegar-Mestric Z, Perkov S, Andrisic L, Tatzber F, Zarkovic N, Duic Z. Trace elements and oxidative stress in hypertensive disorders of pregnancy. Arch Gynecol Obstet. 2013; 287:1924. [PubMed: 22878906] 
32. Kolusari A, Kurdoglu M, Yildizhan R, Adali E, Edirne T, Cebi A, Demir H, Yoruk IH. Catalase activity, serum trace element and heavy metal concentrations, and vitamin A, D and E levels in pre-eclampsia. J Int Med Res. 2008; 36:1335-41. [PubMed: 19094444]

33. Mistry HD, Gill CA, Kurlak LO, Seed PT, Hesketh JE, Meplan C, et al. Association between maternal micronutrient status, oxidative stress, and common genetic variants in antioxidant enzymes at 15 weeks gestation in nulliparous women who subsequently develop preeclampsia. Free Radic Biol Med. 2015; 78:147-55. [PubMed: 25463281]

34. Turnlund JR, King JC, Gong B, Keyes WR, Michel MC. A stable isotope study of copper absorption in young men: effect of phytate and alpha-cellulose. Am J Clin Nutr. 1985; 42:18-23. [PubMed: 2990188]

35. Friel JK, Aziz K, Andrews WL, Serfass RE. Iron absorption and oxidant stress during erythropoietin therapy in very low birth weight premature infants: a cohort study. BMC Pediatr. 2005; 5:29. [PubMed: 16080798]

36. Turnlund JR, Keyes WR, Hudson CA, Betschart AA, Kretsch MJ, Sauberlich HE. A stable-isotope study of zinc, copper, and iron absorption and retention by young women fed vitamin B-6deficient diets. Am J Clin Nutr. 1991; 54:1059-64. [PubMed: 1957821]

37. Cercamondi CI, Egli IM, Mitchikpe E, Tossou F, Zeder C, Hounhouigan JD, Hurrell RF. Total iron absorption by young women from iron-biofortified pearl millet composite meals is double that from regular millet meals but less than that from post-harvest iron-fortified millet meals. J Nutr. 2013; 143:1376-82. [PubMed: 23884388]

38. Mahomed K, Williams MA, Woelk GB, Mudzamiri S, Madzime S, King IB, Bankson DD. Leukocyte selenium, zinc, and copper concentrations in preeclamptic and normotensive pregnant women. Biol Trace Elem Res. 2000; 75:107-18. [PubMed: 11051601]

39. Borella P, Szilagyi A, Than G, Csaba I, Giardino A, Facchinetti F. Maternal plasma concentrations of magnesium, calcium, zinc and copper in normal and pathological pregnancies. Sci Total Environ. 1990; 99:67-76. [PubMed: 2270473]

40. Vargas Zapata CL, Trugo NM, Donangelo CM. Zinc uptake by human placental microvillous membrane vesicles: effects of gestational age and maternal serum zinc levels. Biol Trace Elem Res. 2000; 73:127-37. [PubMed: 11049205]

41. Uriu-Hare JY, Walter RM Jr, Keen CL. 65zinc metabolism is altered during diabetic pregnancy in rats. J Nutr. 1992; 122:1988-98. [PubMed: 1527640]

42. Engle-Stone R, Ndjebayi AO, Nankap M, Killilea DW, Brown KH. Stunting prevalence, plasma zinc concentrations, and dietary zinc intakes in a nationally representative sample suggest a high risk of zinc deficiency among women and young children in Cameroon. J Nutr. 2014; 144:382-91. [PubMed: 24453129]

43. Prasad AS. Zinc: mechanisms of host defense. J Nutr. 2007; 137:1345-9. [PubMed: 17449604]

44. Soran H, Hama S, Yadav R, Durrington PN. HDL functionality. Curr Opin Lipidol. 2012; 23:35366. [PubMed: 22732521]

45. Sampaio E, Barbosa DS, Mazzuco TL, Nunes VS, Passarelli M, Nakandakare ER, Carrilho AJ. Impaired antioxidant action of high density lipoprotein in patients with type 1 diabetes with normoalbuminuria and microalbuminuria. Diabetes Res Clin Pract. 2013; 99:321-6. [PubMed: 23394721]

46. Fainaru O, Lichtenberg D, Pinchuk I, Almog B, Gamzu R, Kupferminc M. Preeclampsia is associated with increased susceptibility of serum lipids to copper-induced peroxidation in vitro. Acta Obstet Gynecol Scand. 2003; 82:711-5. [PubMed: 12848641]

47. Hughes $S$, Samman $S$. The effect of zinc supplementation in humans on plasma lipids, antioxidant status and thrombogenesis. J Am Coll Nutr. 2006; 25:285-91. [PubMed: 16943449]

48. Al-Saleh E, Nandakumaran M, Al-Shammari M, Makhseed M, Sadan T, Harouny A. Maternalfetal status of copper, iron, molybdenum, selenium and zinc in insulin-dependent diabetic pregnancies. Arch Gynecol Obstet. 2005; 271:212-7. [PubMed: 15175885]

49. Christian P, Murray-Kolb LE, Khatry SK, Katz J, Schaefer BA, Cole PM, Leclerq SC, Tielsch JM. Prenatal micronutrient supplementation and intellectual and motor function in early school-aged children in Nepal. JAMA. 2010; 304:2716-23. [PubMed: 21177506] 
50. Shankar AH, Jahari AB, Sebayang SK, Aditiawarman, Apriatni M, Harefa B, et al. Effect of maternal multiple micronutrient supplementation on fetal loss and infant death in Indonesia: a double-blind cluster-randomised trial. Lancet. 2008; 371:215-27. [PubMed: 18207017]

51. Rumiris D, Purwosunu Y, Wibowo N, Farina A, Sekizawa A. Lower rate of preeclampsia after antioxidant supplementation in pregnant women with low antioxidant status. Hypertens Pregnancy. 2006; 25:241-53. [PubMed: 17065044]

52. Wibowo N, Purwosunu Y, Sekizawa A, Farina A, Idriansyah L, Fitriana I. Antioxidant supplementation in pregnant women with low antioxidant status. J Obstet Gynaecol Res. 2012; 38:1152-61. [PubMed: 22563751] 

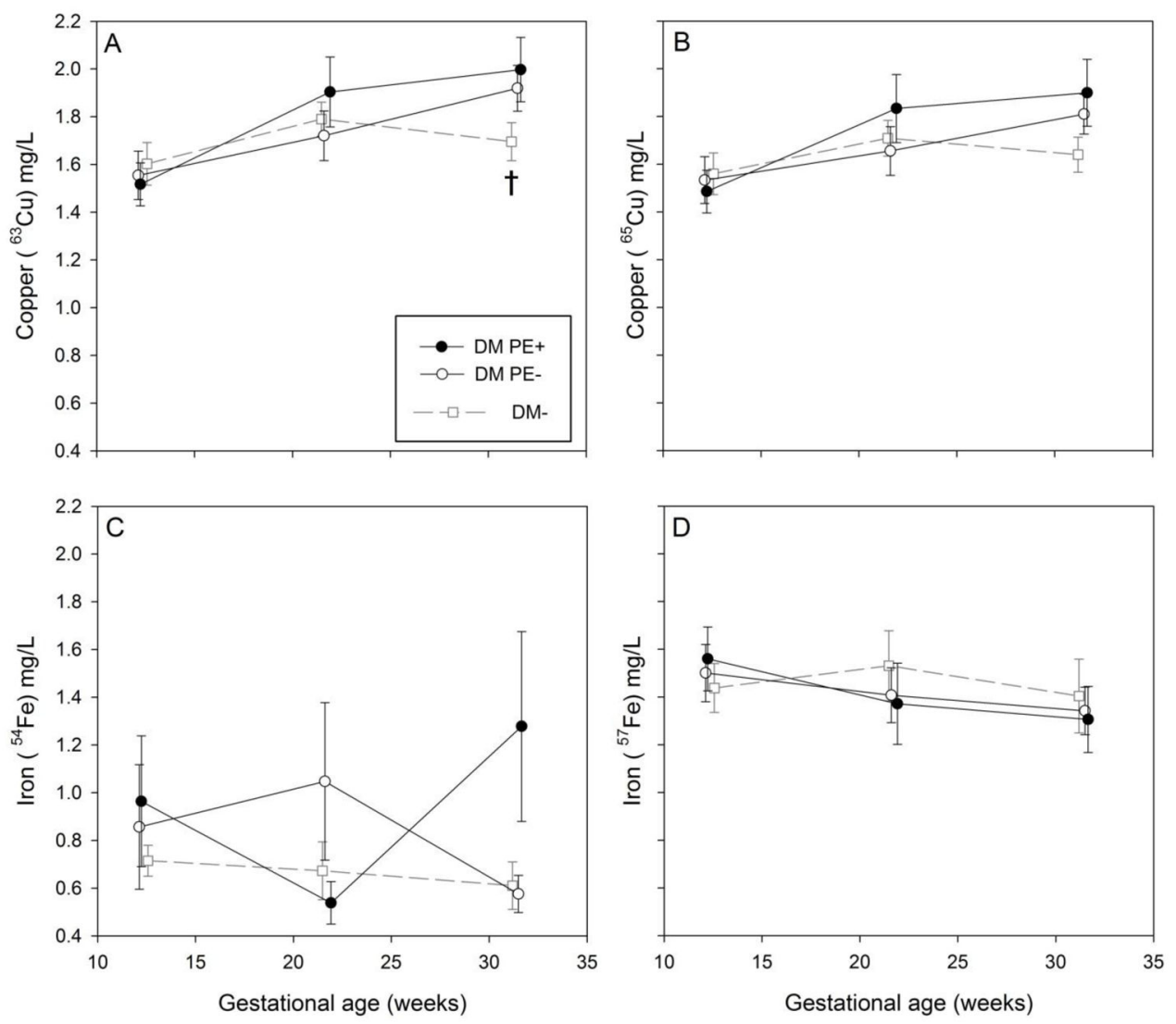

Fig. 1.

Associations of maternal plasma copper (A, B) and iron (C, D) in T1DM women who subsequently developed PE (DM PE+, n=23) vs. those who did not (DM PE-, n=24). Nondiabetic women $(\mathrm{DM}-, \mathrm{n}=19)$ used as a reference control.

Values represent means $\pm \mathrm{SE}$. $\dagger \mathrm{P}<0.05$, DM PE- vs. DM-

Generalized estimating equations (GEEs) for between group analyses at each visit and throughout gestation (overall). Overall differences not significant for any variable. 

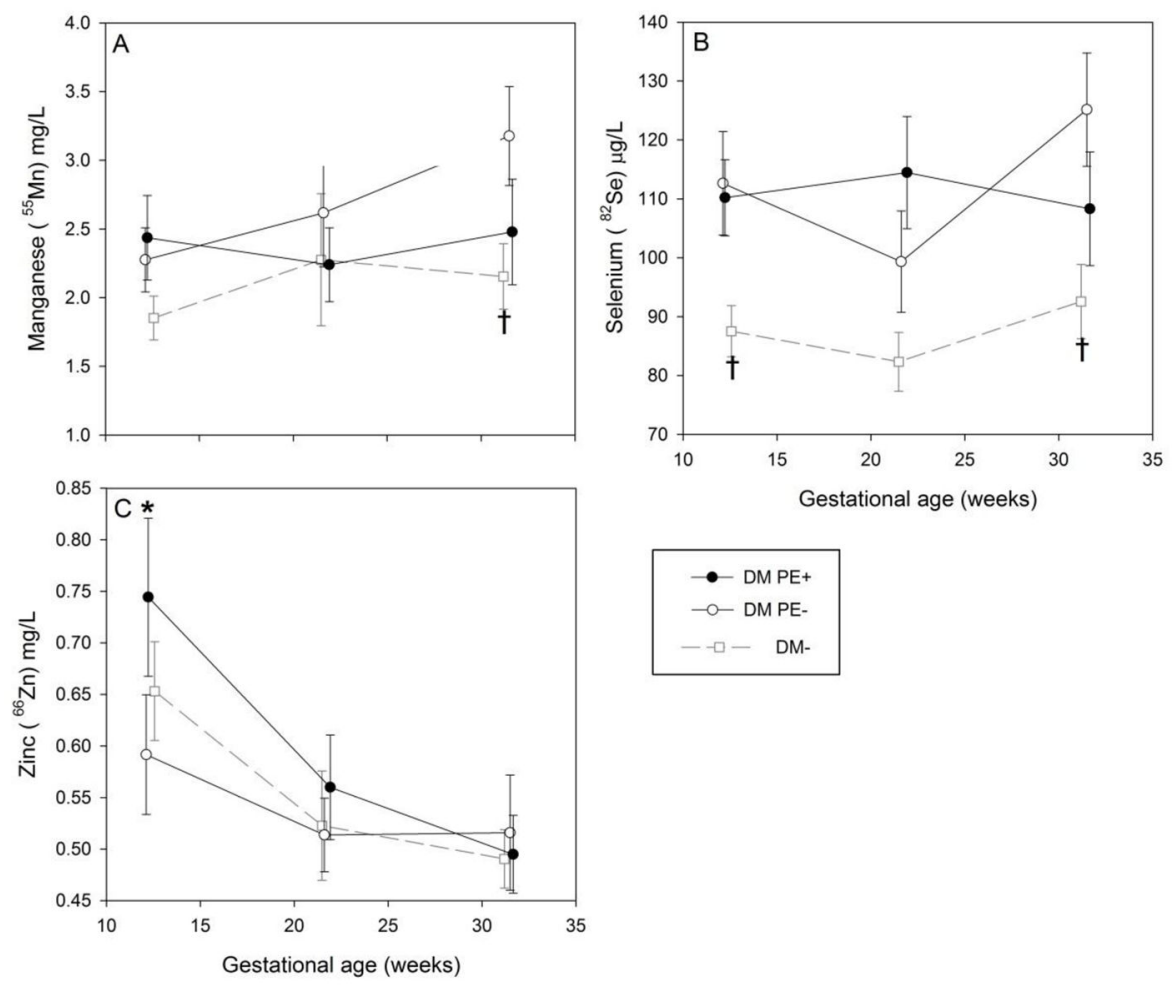

Fig. 2.

Associations of maternal plasma manganese (A), selenium (B) and zinc (C) with in T1DM women who subsequently developed PE (DM PE+, n=23) vs. those who did not (DM PE, $\mathrm{n}=24)$. Non-diabetic women $(\mathrm{DM}-, \mathrm{n}=19)$ used as a reference control. Overall, differences in manganese and selenium for DM PE- vs. DM- were significant, $\mathrm{P}<0.05$.

Values represent means $\pm \mathrm{SE}$.

* $\mathrm{P}<0.05$, DM PE+ vs. DM PE-

Generalized estimating equations (GEEs) for between group analyses at each visit and throughout gestation (overall). 

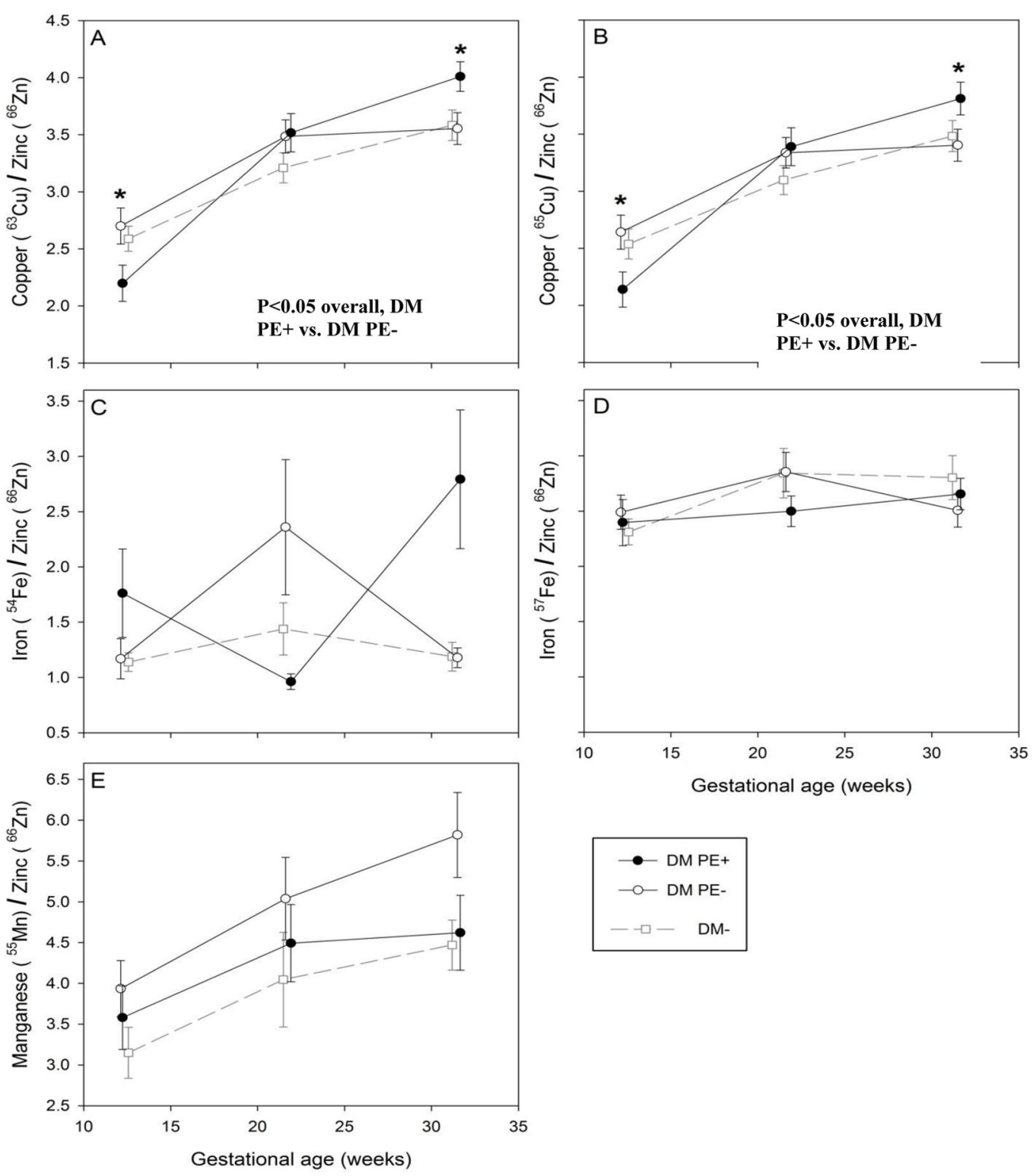

Fig. 3.

Associations of maternal plasma copper: zinc (A, B), iron: zinc (C, D) and manganese: zinc (E) in T1DM women who subsequently developed PE (DM PE+, n=23) vs. those who did not (DM PE-, n=24). Non-diabetic women (DM-, n=19) used as a reference control. Values represent means \pm SE. Overall, differences in copper: zinc ratios for DM PE+ vs. DM $\mathrm{PE}-$ were significant, $\mathrm{P}<0.05$.

* $\mathrm{P}<0.05, \mathrm{DM}$ PE+ vs. DM PE-

Generalized estimating equations (GEEs) for between group analyses at each visit and throughout gestation (overall). 

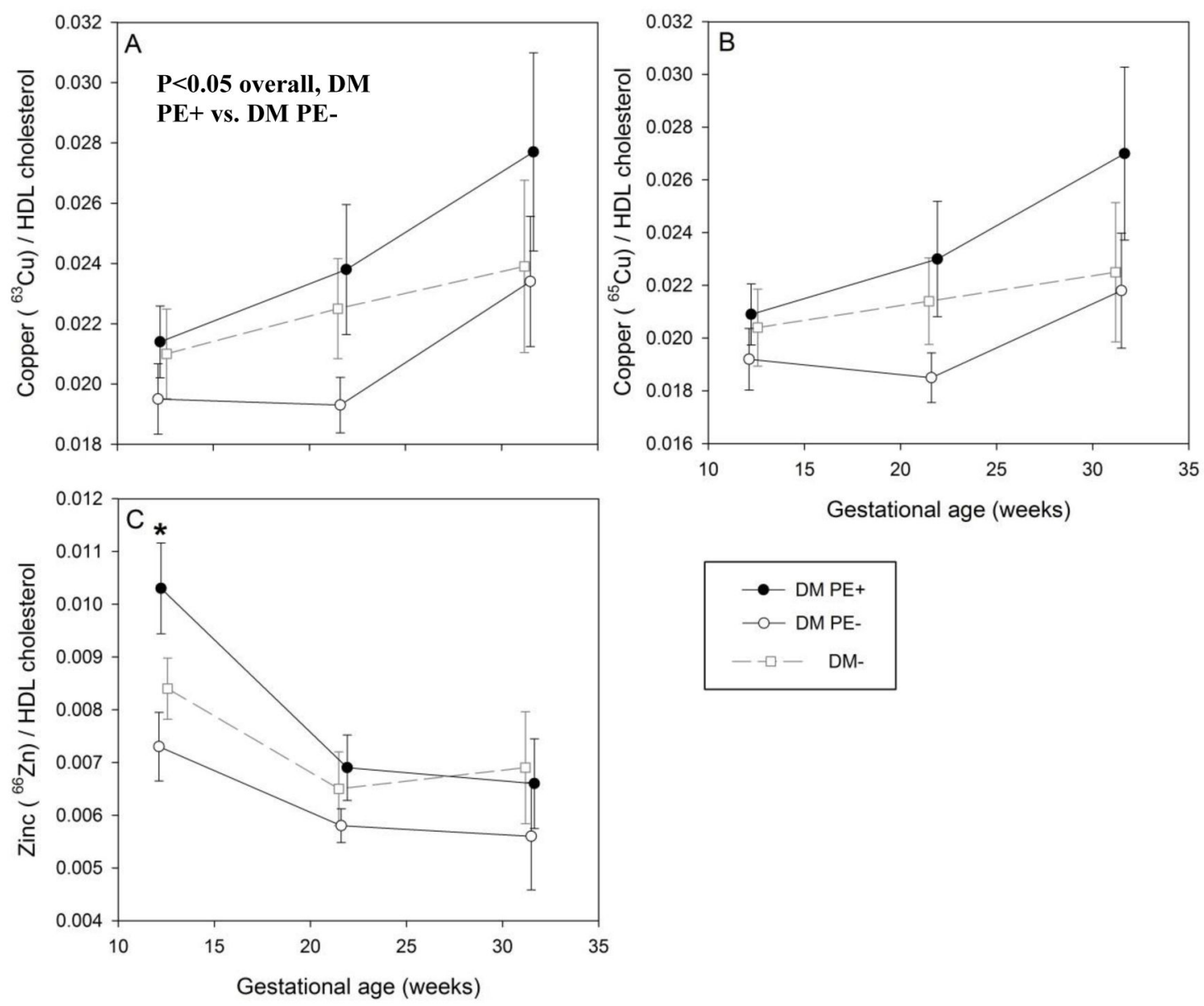

Fig. 4.

Associations of maternal plasma copper: HDL cholesterol (A, B), and zinc:HDL cholesterol (C) in T1DM women who subsequently developed PE (DM PE+, n=23) vs. those who did not (DM PE-, n=24). Non-diabetic women (DM-, $n=19)$ used as a reference control.

Overall differences in copper: HDL cholesterol (both isotopes) and zinc:HDL cholesterol for DM PE+ vs. DM PE- were significant, $\mathrm{P}<0.05$.

Values represent means $\pm \mathrm{SE}$.

* $\mathrm{P}<0.05$, DM PE+ vs. DM PE-

Generalized estimating equations (GEEs) for between group analyses at each visit and throughout gestation (overall). 


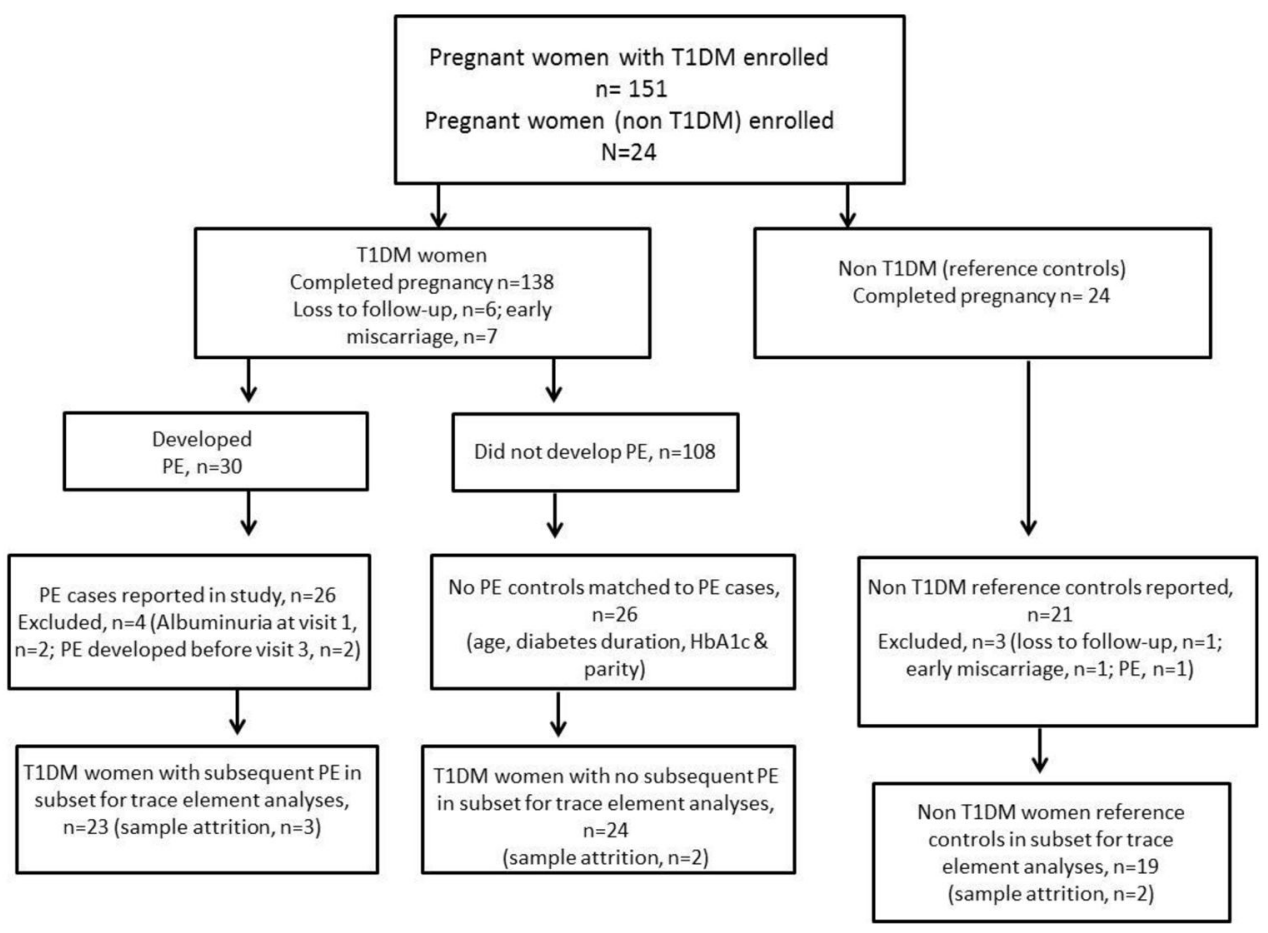

Fig. 5.

Study design and selection of participants

PE, preeclampsia; T1DM, type 1 diabetes mellitus 


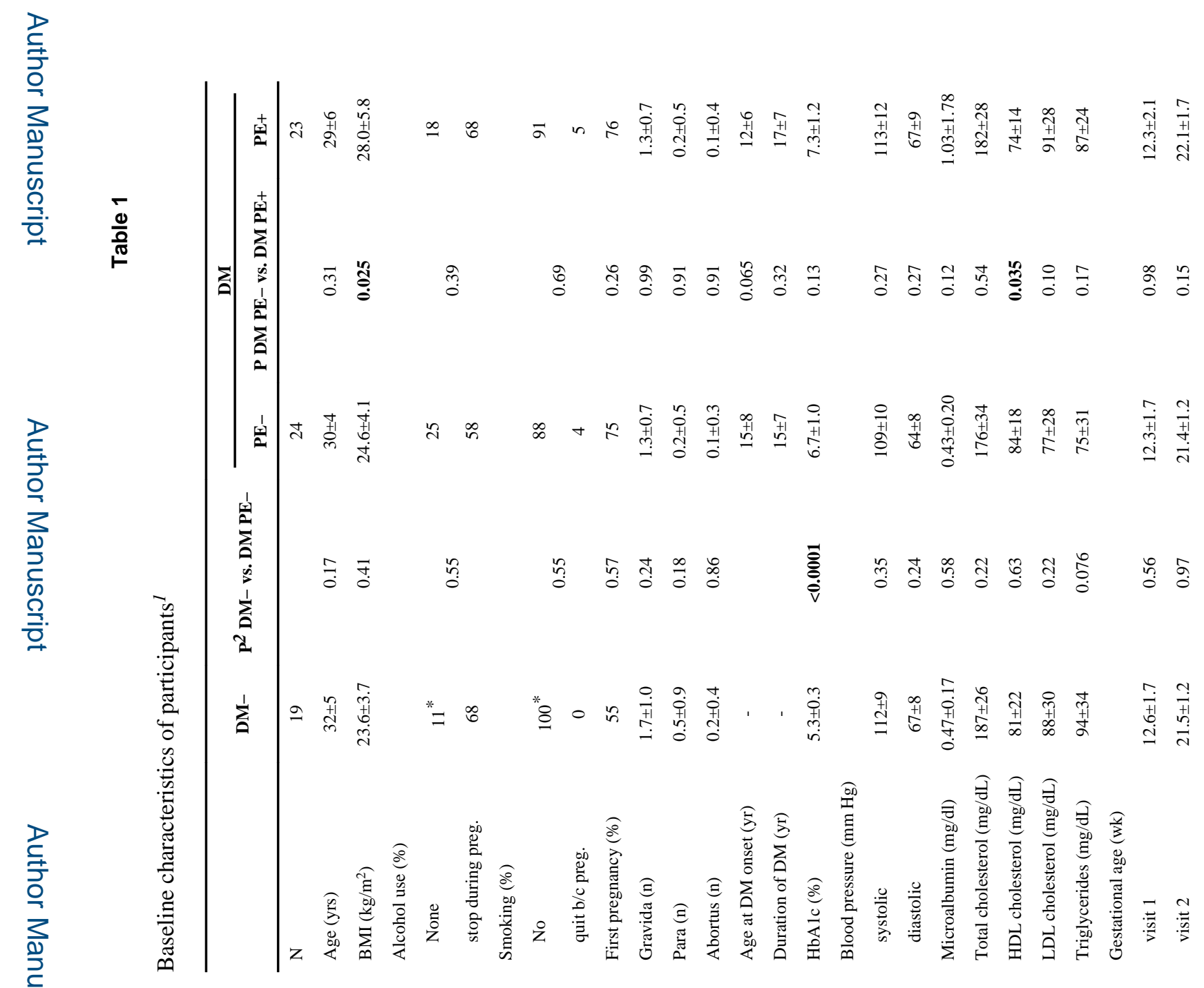



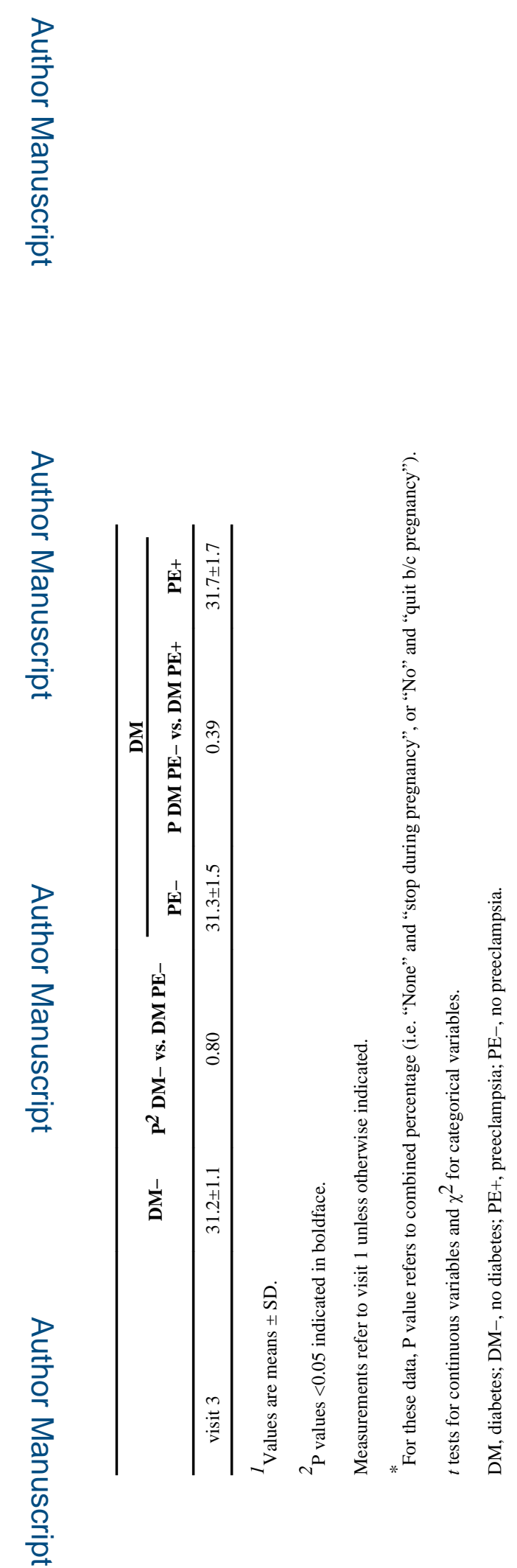

Nutr Res. Author manuscript; available in PMC 2016 May 01. 